\title{
QUEEN'S
UNIVERSITY
BELFAST
}

\section{The inclusion of open-ended questions on quantitative surveys of children: Dealing with unanticipated responses relating to child abuse and neglect}

Lloyd, K., \& Devine, P. (2015). The inclusion of open-ended questions on quantitative surveys of children:

Dealing with unanticipated responses relating to child abuse and neglect. Child abuse \& neglect, 48, 200-207. https://doi.org/10.1016/j.chiabu.2015.03.021

\section{Published in:}

Child abuse \& neglect

\section{Document Version:}

Peer reviewed version

Queen's University Belfast - Research Portal:

Link to publication record in Queen's University Belfast Research Portal

\begin{abstract}
Publisher rights
Copyright @ 2015 Elsevier Ltd. All rights reserved.

This is the author's version of a work that was accepted for publication in Child Abuse \& Neglect. Changes resulting from the publishing process, such as peer review, editing, corrections, structural formatting, and other quality control mechanisms may not be reflected in this document. Changes may have been made to this work since it was submitted for publication. A definitive version was subsequently published in Child Abuse \& Neglect, [VOL\#, ISSUE\#, (DATE)], doi:10.1016/j.chiabu.2015.03.021

General rights

Copyright for the publications made accessible via the Queen's University Belfast Research Portal is retained by the author(s) and / or other copyright owners and it is a condition of accessing these publications that users recognise and abide by the legal requirements associated
\end{abstract} with these rights.

\section{Take down policy}

The Research Portal is Queen's institutional repository that provides access to Queen's research output. Every effort has been made to ensure that content in the Research Portal does not infringe any person's rights, or applicable UK laws. If you discover content in the Research Portal that you believe breaches copyright or violates any law, please contact openaccess@qub.ac.uk. 
The inclusion of open-ended questions on quantitative surveys of children: Dealing with unanticipated responses relating to child abuse and neglect

\begin{abstract}
Web surveys have been shown to be a viable, and relatively inexpensive, method of data collection with children. For this reason, the Kids’ Life and Times (KLT) was developed as an annual online survey of 10 and 11 year old children. Each year, approximately 4,000 children participate in the survey. Throughout the six years that KLT has been running, a range of questions has been asked that are both policy-relevant and important to the lives of children. Given the method employed by the survey, no extremely sensitive questions that might cause the children distress are included. The majority of questions on KLT are closed yielding quantitative data that are analysed statistically; however, one regular open-ended question is included at the end of KLT each year so that the children can suggest questions that they think should be asked on the survey the following year. While most of the responses are innocuous, each year a small minority of children suggest questions on child abuse and neglect. This paper reports the responses to this question and reflects on how researchers can, and should, deal with this issue from both a methodological and an ethical perspective.
\end{abstract}

Keywords: Abuse, Ethics, On-line survey; Open-ended questions 
The inclusion of open-ended questions on quantitative surveys of children: Dealing with unanticipated responses relating to child abuse and neglect

\section{Introduction}

Large-scale random sample surveys have become an accepted method of collecting quantitative data from children and young people in countries across the world (Livingstone, Haddon, Görzig \& Ólafsson, 2011; Roberts et al, 2007), an approach that has been greatly enhanced by the growing availability of computers (World Economic Forum, 2012). A number of large-scale surveys employing Computer Assisted Personal Interviews (CAPI) or Computer Assisted Self-Interviews (CASI) have been used to collect data from children (Livingstone et al., 2011; Radford, Corral, Bradley \& Fisher, 2013); however, this method can be expensive and time consuming. One way of exploiting the advantages of computer surveys with children, while eliminating the costs associated with administering them with an interviewer present, is to use the internet. Online surveys have been shown to be a viable method of data collection with children and young people (Goodman, 2013; Heiervang \& Goodman, 2011; Lundy \& McEvoy, 2008; Madge et al., 2012; Shields, 2003; Tilbury, Gallegos, Abernethie \& Dziurawiec, 2008). For this reason, the Kids’ Life and Times (KLT) was established in 2008 as an annual online survey of children who are in their final year of primary (elementary) school and who are all 10 or 11 years of age.

KLT is an anonymous survey consisting of (mostly) closed questions on topics that have included attitudes to school, health and wellbeing, use of technology and children's perceptions of their rights. In general, the survey seeks to avoid potentially very sensitive questions given the age of the children and the remote, online data collection method employed. This is important since there is no contact between the respondents and the 
researchers which means that non-verbal cues, such as respondent discomfort are lost (Black \& Ponirakis, 2000; Nicholas et al., 2010). Furthermore, depending on the location of the computers in schools, there may be no available support if the questions raise sensitive issues that upset the children. However, over the past few years of KLT it has become clear that the inclusion of an open-ended question at the end of the survey has elicited responses relating to child abuse and neglect which have raised methodological and ethical issues that are explored in this paper.

\section{Researching sensitive issues on surveys with children}

A number of studies reported in the literature have specifically addressed sensitive topics including child abuse and neglect among children and young people using the survey method (Amaya-Jackson, Socolar, Hunter, Runyan \& Colindres, 2000; Carroll-Lind et al, 2006;

Ellonen \& Poso, 2011; Finkelhor, Vanderminden, Turner, Hamby, \& Shattuck, 2014; Gallagher, Bradford, \& Pease, 2002; Radford et al., 2013). In the majority of these studies, the respondents, their parents/caregivers and teachers were informed about the sensitive nature of the research. The authors also highlighted the ethical issues involved in carrying out surveys on sensitive topics with children and ensured that emotional support was available for their young participants (Carroll-Lind, Chapman, Gregory \& Maxwell, 2006; Ellonen \& Poso, 2011; Finkelhor et al., 2014; Gallagher et al., 2002; Radford et al., 2013). This is particularly important in anonymous online surveys of children asking questions specifically about abuse and neglect where it would not be possible for researchers to identify individual respondents (Ellonen \& Poso, 2011). The problem is, however, how researchers can and should deal with unanticipated sensitive responses to open-ended questions in anonymous online surveys of children covering what could be considered more ‘benign’ topics? 
While there appears to be a dearth of information on this subject, the findings from three studies reported in the literature using anonymous online surveys with young people that included open-ended questions are particularly notable. In a study exploring the educational experiences of adolescents aged 12 to 18 years in America ( $7^{\text {th }}$ to $12^{\text {th }}$ graders), which used a mixed-method of online and paper questionnaires as well as face-to-face interviews, Shields (2003) reported data from two open-ended questions 'Tell me a story about the best teacher you ever had' and 'Tell me a story about the worst teacher you ever had.' She found that many students participating in the anonymous web survey 'went beyond the provision of rich and detailed description to take some degree of personal risk by sharing details about their personal or family situations' (p. 406). However, while Shields noted that some students in the face-to-face interviews revealed sensitive data such as particular teachers being racist or in one case 'Touches you' (p. 407), no information was provided on the particular types of personal or family information the young people disclosed in the web survey, whether it was sensitive and, if so, how it was handled. Shields also included a final general question on her web survey which asked the students if there was anything else they wanted to say about their school experience; once again, however, no findings from this question are included in the paper, therefore it is not clear whether or not sensitive data were reported by the participants.

Reporting of sensitive data by young people was an issue encountered by researchers carrying out an anonymous online survey looking at family meal practices among 15 year olds in Australia (Tilbury et al., 2008). Tilbury and colleagues included open-ended questions on the survey and reported that some responses, particularly those related to the health and wellbeing questions, gave cause for concern. For example, they reported that some young people mentioned alcohol and drug problems, feeling depressed and being unhappy about their height and weight. While stating that they 'made every attempt to ensure that student 
safety was not at risk', the authors did not provide any information on how they dealt with the issue (Tilbury et al., 2008, p.8). This may reflect the age of the respondents; perhaps there was a belief that these 15 year olds would seek help if they felt this was required.

Furthermore, there was no suggestion from Tilbury et al. that the young people had revealed information relating to sexual abuse, a matter that may have given rise to more concern on the part of the researchers had it occurred.

A recent anonymous online survey of 10,500 pupils in secondary schools (13 to 18 years) exploring the meaning of religion in young people’s lives included two open-ended questions (Madge et al., 2012). The authors reported that many respondents gave 'long and thoughtful answers to the two open-ended 'essay’ questions' (p. 427). However, there was no information on either the question wording, the responses given by the respondents or what use, if any, was made of the data from these open-ended questions. A number of researchers recommend that open-ended questions should only be included in a survey if the responses are to be analysed and used (Boynton \& Greenhalgh, 2004; O'Cathain \& Thomas, 2004). Nonetheless, O'Cathain \& Thomas (2004) do suggest that an important reason for including open-ended 'catch-all' questions on surveys is to allow respondents to record anything they thought may have been missing from the survey. While this is laudable, there are pitfalls as has been demonstrated by Tilbury et al. (2008); namely, the unanticipated sensitive responses to open-ended questions from children and young people and the ethical concerns it raises for researchers.

\section{Ethical concerns in relation to sensitive questions}

All research with human beings, regardless of the age of the participants, needs to address ethical concerns. Furthermore, given their particular vulnerability, there are a number of 
specific ethical issues that need to be considered when carrying out research with children. These include the power-relations between researchers and children, the issue of 'gatekeepers' - who can and should give consent for children's participation in research and the need for children to understand that they can refuse to participate or withdraw from the research without fear of consequences of any kind (Fargas-Malet et al., 2010; HelwegLarsen \& Bøving-Larsen, 2003; Hunleth, 2011; Leonard, 2007). Further, Helweg-Larsen \& Bøving-Larsen (2003, p. 1879) note that when dealing with children, researchers must 'ensure that the study has a minimal impact on the child's physical, mental, and emotional integrity'. This is particularly the case when sensitive topics are included in research with children or when children disclose information that raises concerns for their wellbeing (Fargas-Malet et al., 2010; Morrow 2008).

The overall aim of this paper, therefore, is to describe the unanticipated sensitive responses reported by 10 and 11 year old children taking part in a large-scale online survey and to consider ways in which researchers can deal with the methodological issues and ethical concerns this raises.

\section{Method}

\section{Participants}

Each year, all children in Primary 7 (P7) in Northern Ireland are invited to participate in KLT. P7 pupils are in the final year of their primary (elementary) school education and they are all aged 10 or 11 years. Approximately 4,000 pupils from around 300 primary schools participate in the survey every year. The data for this paper came from combining six years of KLT (2008-2013) resulting in a total of 24,399 cases. 


\section{Questionnaire}

KLT is run on a modular format and over the years questions have been funded by government departments, organisations such as the Northern Ireland Commissioner for Children and Young People (NICCY) and charities. The questions tend to reflect policy interests that are current in the year of the survey and have included children’s rights, nutrition, parental engagement in education and use of technology. Children have also participated in the development of KLT questions in several ways over the years; in focus groups (Lloyd \& Devine, 2010), as co-researchers (Emerson \& Lloyd, 2014), and in pilot testing the questionnaires (Lloyd \& Devine, 2010).

KLT consists of (mostly) closed questions for two main reasons. Firstly, KLT was established specifically to address the lack of a regular and rigorous children's survey that would yield publicly available quantitative data. Secondly, the survey is anonymous and the use of closed questions means that there is less likelihood that children will inadvertently provide personal information that could identify them or potentially sensitive data that the survey tries to avoid given the data collection methods employed. The question used as the basis for this paper is one of the few regular open-ended questions and it is asked at the very end of KLT every year: 'Did we miss anything that was important to ask about? What questions do YOU think should be on the survey for next year's P7 children?'

\section{Procedure}

Each year, schools receive letters, parental consent forms, teacher instructions and bookmarks for every P7 pupil in the weeks prior to the survey going live on the internet in the final term of the school year (April to June). Schools are given a unique identification number so that entries can be associated with a particular school. The children are not asked for their names 
so it is not possible to identify individual pupils. Due to budgetary constraints, there is no direct contact between the researchers and the schools or children. Email reminders are sent to all schools throughout the survey fieldwork period by C2K which is the organisation responsible for delivering computer services to schools in Northern Ireland and is funded by the Department of Education.

Respondents complete the survey in their classroom or in their school's computer room. Each year KLT consists of around 70 questions and takes about 20 minutes to complete; respondents can skip any question they do not want to answer. The method for the survey self-completion online in school - was developed in conjunction with children, parents and school principals following consultations carried out in 2008 (full details of the development of KLT can be found in Lloyd \& Devine, 2010). Each year, participating schools receive an anonymised report containing tables of results for their school but no responses from openended questions. All schools are sent one hard copy of a child-friendly comic style publication of the key results from the survey for each P7 class and are encouraged to use the publication to discuss the issues raised in the survey with the current year's P7 class. Copies of the comic can also be downloaded from the web (www.ark.ac.uk/klt/2013/comic2013.pdf).

\section{Ethical approval}

Initial approval was sought, and given, for the KLT survey to be developed and run in 2008 by the Ethics Committee in the School of Sociology, Social Policy and Social Work at Queen's University Belfast. Subsequently, as the method has remained the same, the Ethics Committee is asked for approval of the questionnaire that will be used in that year and, to date, permission has been given. In seeking, and obtaining, ethical approval for the KLT survey, evidence of the type of questions to be asked was provided. None of the questions 
have been considered particularly sensitive by the Ethics Committee or by the children pilottesting the questionnaires. As required by Queen’s University, consent had to be gained from school principals and from parents/guardians before children could be asked for their own consent. Principals can view a paper version of the questionnaire on the KLT website before consenting (or not) to their school's participation. Parents are provided with information on the survey and asked to complete, and return, a consent form to the school. Finally, and most importantly, the children are also asked to give their consent at the start of KLT; if they do not want to participate, regardless of whether or not the gatekeepers have consented, they can click out of the survey before any questions appear. Therefore, the children who take part in the survey are those for whom permission has been obtained from school, parent/guardian and child (Lloyd \& Devine, 2010).

\section{Findings from the KLT open-ended question 2008-2013}

The combined dataset used for this paper contained 24,399 cases of which 46 per cent were boys and 54 per cent girls. This reflects the gender difference in the survey response in each year with more girls completing KLT than boys. Forty per cent of respondents provided suggestions for the following year's survey, 60 per cent of whom were girls.

Of the children who respond to the final open-ended question each year, the vast majority provide what could be considered 'innocuous' suggestions on the general themes of school (including teachers, subjects, feelings about moving to high school); activities such as sports and hobbies, family structure (who they live with, number of brothers and sisters); friends; pets; appearance; and use of technology. Specific examples of the type of questions asked include: 
The type of sports they like.

What you want to be when you grow up.

Ask about their pets.

Ask more questions about their friends.

I think you should ask questions about how they feel about the way they look.

How much do you use your computer at home?

The environment, technology, TV, and family.

Ask about after school activities.

The decision as to which of the children's suggestions are included in the following year's survey depends on several factors; the number of respondents who mention that question or topic ( $10 \%$ or more for questions that have not already been included in KLT surveys) and whether the topic is one that, although suggested by only two or three respondents, is rarely asked on large-scale surveys of children such as caring responsibilities and attitudes to childcare (Lloyd, 2012a; Lloyd, 2012b). (www.ark.ac.uk/klt/results/kltmodule.html).

However, in each year since the first survey in 2008, approximately three percent of KLT respondents suggest questions that are considered too sensitive to ask in the survey. Most of these relate to personal information about the children themselves or about their family circumstances such as:

I think you should have asked if they have a mental condition because I do, it's a food phobia.

Do kids ever get called nerd or dumbo or idiot because of their intellectual ability? Has your mum and dad split up and did they think of your feelings in this? 
Has your mum and dad split up? How did you feel? Do you ever feel as if it is your fault? Do you ever wish they would get back together?

Do your parents fight?

A section on family problems.

Is your parent an alcoholic?

While impossible to verify because of the survey method employed by KLT, suggestions such as these are likely to reflect what is actually happening in the lives of the children making them. More worrying still, however, is the very small number of children in each year group (approximately 1\%) who suggest that the following year's survey should include questions on extremely sensitive issues including specific mention of child abuse and neglect. There has been no change in this figure across the six years of KLT. Combining all the openended responses from KLT between 2008 and 2013 which relate to suggested questions on issues related to child neglect and cruelty or child abuse resulted in 196 cases from the total of 24,399 children (approximately 1\%). Of these, 67 per cent were girls.

\section{Suggested questions on abuse and neglect}

Examples of children's suggestions for the following year's survey in relation to abuse and neglect are as follows:

I think you should ask if you ever felt threatened or scared at home.

Have you been hurt by someone like your parents or guardians?

Have you ever been child abused?

Does any of your family child abuse you in any way?

Are you getting abused by your parents?

Are you being abused? 
Do one [or both] of your parents abuse you?

Do your parents take you out with them or leave you alone in the house on your own? Has anyone ever left you at home unattended?

Have you felt depressed? Do you ever feel like no one cares?

Have you ever felt alone just enough to kill yourself?

Is anything bad happening to you at home?

If we were being physically abused at home or if your mum or dad has a drink or drugs problem.

Once again, it may be that these suggestions represent the lived experiences of the children making them; however, this is not always as clear-cut as might at first appear. For example, some children have mentioned sexual abuse or neglect within the context of other issues that they are suggesting 'Put a couple of questions about bullying and what kind of bullying and something to do with child abuse.' It is possible that children may have heard adults discussing the issue of abuse or they have heard items about it in the media. This is particularly true when abuse is at the forefront of news items such as the recent high level of publicity in the United Kingdom on what has been called the 'Jimmy Saville Scandal' (BBC 2014). Jimmy Saville was an English media celebrity who had access to children through his television and charity work; after his death in 2011, hundreds of allegations of sexual abuse of children and young people were made, and are still being made, against him. Indeed one child participating in the 2013 KLT asked 'Who was jimmy saviel??????????’ Despite the misspelling of the name, it is clear to whom the child is referring. While it is important to appreciate that some children requesting questions on abuse or neglect may not be experiencing them personally, consideration has to be given to the possibility that others may be. 


\section{Discussion}

The findings from KLT support those of Tilbury et al. (2008) with teenagers and suggest that when children are provided with the opportunity to respond to open-ended questions on anonymous surveys, there is the possibility that they will reveal sensitive or personal information. Given the dearth of material in the research literature on this topic, it is unclear whether this is something that does happen in other surveys in response to general openended questions but is not reported, or whether it depends very much on how the question is framed. In the case of KLT, we are specifically requesting that the children suggest future topics for the survey. Therefore it is perhaps unsurprising that sensitive issues, whether relating specifically to the respondents themselves, or to things that are occurring around them in their daily lives, are raised. The question for us, as researchers, is how do we deal with this?

One possibility is to ignore the data from this open-ended question; sensitive questions like some of those requested would not be asked on KLT as they are inappropriate for the online survey method employed. However, researchers such as Boynton \& Greenhalgh (2004) and O'Cathain \& Thomas (2004) have argued that open-ended questions should not be included on a survey unless the responses are analysed. While the responses to this KLT open-ended question are not analysed for dissemination of the findings, they are used to ensure that some of the children's suggestions are included in the following year's survey.

Another possibility is not to include the question and instead involve children in the development of the questionnaire as co-researchers and focus group participants, as happens in some years of KLT. This does give more control over the potential responses, and allows support from a trusted adult to be provided if sensitive issues are raised. There are several 
drawbacks with not including the question on KLT. One is that there would be fewer, potentially less representative, respondents suggesting topics than is possible with the largescale survey open-ended question. In addition, and in line with the views of Ellonen \& Poso (2011) and Carroll-Lind et al. (2006) it is important for children's voices to be heard in research dealing with sensitive issues. Nonetheless, this does need to be weighed against the perhaps more pressing issue of the ethical concerns raised by the sensitive responses given by some children in anonymous surveys.

\section{Ethical concerns}

Each year, ethical approval is sought, and obtained, from Queen’s University; however, this is based on the questions asked in the survey, not on the potential responses we may get. The question is whether it is ethical to ignore what may, potentially, be a serious issue for some KLT respondents? Researchers have a duty of care to protect all participants from physical and/or psychological harm (Lewis \& Lindsay, 2000); therefore, the most intuitive course of action would be to locate the children who suggest these topics and explore their reasons. However, this needs to be balanced against issues relating to privacy and confidentiality (Tilbury et al., 2008). According to Mudaly \& Goddard (2009, p. 273) ‘protection of privacy is a basic right of all research participants and assuring anonymity is one way to do this'. They note, however, that 'this becomes a problem when the research is about child abuse and when it involves children who have been abused' (p. 273). In their study, they were carrying out qualitative research with children who had been abused. This is clearly different from anonymous quantitative surveys of children who may, or may not, have suffered abuse. Nonetheless, KLT participants are told at the start of the survey (by the animated character reading out the introductory section) that their 'parents, friends or teachers will not see your answers'. However, they are not told that anything sensitive that they raise will be disclosed 
given that we do not ask their name and have no way of identifying them. The dilemma, though, is that if children are being abused or neglected, the survey may be seen by them as an opportunity to tell someone who can perhaps do something about it (Amaya-Jackson et al., 2000); on the other hand, we do not know who the children are.

This dilemma is captured well in the following two quotes from the KLT respondents: 'I think you should ask the children more about their bullies/being bullied, they can feel confident doing a survey without giving out names/personal information.'

'I think there should be a question that says if you have been hit or abused by anybody because then the adults can put a stop to child abuse.'

While the first quote does not relate specifically to abuse but rather to bullying, nonetheless, it is important as the child is acknowledging the confidence that anonymity can provide in allowing children to report sensitive issues which supports the views of researchers such as Shields (2003) and Nicholas et al. (2010). The second quote is particularly poignant as the participant clearly believes that once a child tells an adult about abuse then something will be done about it; this reflects the advice given to children by teachers, parents and organisations such as Childline. This latter quote does, in fact, raise two serious matters in relation to KLT. The first is anonymity: the children do not give their name when completing the survey, and so it is not possible for us to identify them. The second is that while we do know the school they attend which could, potentially, enable us to discuss the issue with the principals to try to identify these children, the timing of the 2008 to 2013 KLT surveys means that the participants will have already left the school when the data have been analysed. This is a serious restriction; even if it were reasonable to overcome the confidentiality issue the children would no longer attend that school. 


\section{Dealing with the dilemma}

The core question thus becomes one of identifying what obligation researchers have in terms of dealing with this issue. These sensitive responses first came to light during analysis of the 2008 survey when seeking to identify questions to include in the following year's survey. At that time, we decided to hold back from taking further action until we had more data. When similar responses emerged in subsequent years, we initially discussed the possibility of providing telephone numbers of appropriate helplines, such as Childline, at the end of the survey. The drawback with that was that this is an online survey which many children complete in a computer room with their classmates around them. If they were seen to write down telephone numbers, this could compromise their confidentiality. Furthermore, they may not have a pen/pencil with them in the computer room, which could leave them feeling anxious or upset that help was available but they would have to try to remember the telephone number/website address. Linking them directly to a website was another option considered, but again, it was felt this could compromise their confidentiality.

Advice was sought from a colleague in the Social Work department at Queen’s University. Their suggestion was that if this continued to be an issue, we could consider contacting the schools the children attended, or indeed all participating schools, to alert them to the fact that some KLT respondents were suggesting topics such as abuse or neglect as potential questions for the survey. Other options we considered included supplying schools with leaflets about child abuse and requesting that a teacher or pastoral care staff member should be present when the children completed the survey as support if necessary. However, in the tradition of what Bell (2004) has called the ‘owning up’ genre of describing the dirty work of data collection (cited in Tilbury et al., 2008 p. 469), our concern was that if principals and parents became aware that such sensitive matters were being raised by children participating in the 
survey, even though they were not specific questions being asked, it could jeopardise the future of KLT. This is something we were reluctant to do, given the importance and uniqueness of the survey in providing a vehicle to record children's views on issues that affect their lives. Indeed, as Morrow \& Richards (1996, p. 97) note, an 'overly protective stance towards children may have the effect of reducing children's potential to participate in research'.

On a more promising note, it is clear that the issue of child abuse is being addressed by many primary schools in the UK and elsewhere across the world (Baker, Gleason, Naai1, Mitchell, \& Trecker, 2012; BBC, 2013; Goldman, 2011; Office of the Children’s Commissioner, 2012; Stephenson, McElearney, \& Stead, 2011). Research from these authors indicates that this is being done using a variety of approaches including through curriculum activities, assemblies and presentations by external organisations. However, there is also evidence that some schools are not teaching children 'how to keep safe from violence in the home, and how to identify appropriate and inappropriate touch’ (Stephenson et al., 2011, p. 13) something which is included in the key recommendations of the report produced by these authors. Given that some KLT respondents mention abuse and neglect in the context of home and parents, this is something that schools do need to address.

\section{Addressing the issue in future KLT surveys}

The 2014 KLT survey is underway and there are two changes this year - one methodological and one ethical - that have the potential for helping us to at least begin to address the issue. The first, methodological, change is the date of the survey fieldwork; between 2008 and 2013, KLT was carried out in the summer term (between April and June) which, as noted earlier, meant that the P7 children were no longer at that school when the data were analysed. 
The fieldwork dates for future KLT surveys, beginning in 2014, have been changed to November and December which means the participants will still be at the school when the survey data are analysed and reports sent to the principals. The second, ethical, change is that the introductory text to the question asking children for suggestions for the following year's survey will include a sentence explaining that a list of the children's ideas for future questions will be sent to their school but because we do not have the respondent's name no one will know who particular suggestions came from. A summary of the responses to this question will be added to the confidential report that is sent to participating schools. Given the reluctance of many primary schools to discuss the issue of abuse and neglect at home, as identified by Stephenson et al., (2011), this is an appropriate, and timely, way of reinforcing the need for this sensitive topic to be raised and dealt with in school. The participants to the 2014 KLT survey will still be attending the school and therefore able to be involved in any programmes addressing sensitive issues. Equally importantly, there is no compromise to the guarantee of anonymity to the children. Whether alerting principals to the sensitive responses given by some children in their school affects future support for KLT from those schools remains to be seen.

\section{Conclusion}

The increasing availability of the internet provides quantitative researchers with a new mode of administration for large-scale surveys with a ‘net generation’ (Tapscott, 1998) of children and young people who are familiar with, and enjoy using, this technology (Nicholas et al., 2010). Lee \& Lee (2012) note that the anonymity associated with web-based surveys is one of the benefits reported by some researchers represented in their 10-year review of research on sensitive issues. However, the lack of contact between researcher and respondent means that surveys have to be carefully designed and, as this paper has demonstrated, consideration 
should be given to the ethical issues that may arise from potentially sensitive responses elicited from what appear to be 'benign' questions. This is not just an issue for quantitative researchers; for example, online focus groups are becoming increasingly common (Lee and Lee, 2012) and it is our contention that the use of this qualitative method with, potentially anonymous, children (Nicholas et al., 2010) also raises the possibility of disclosure of sensitive information from participants. In light of this, and given the scarcity of research literature on the issue, it is perhaps timely for it to be more widely debated. The aim of this paper is to begin that process in the hope that researchers will share their experiences of sensitive disclosure in anonymous research among children and young people and explain whether, and how, they dealt with it.

\section{References}

Amaya-Jackson L., Socolar R., Hunter W, Runyan, D. K. \& Colindres, R. (2000). Directly questioning children and adolescents about maltreatment. A review of survey measures used. Journal of Interpersonal Violence, 15, 725-759.

Baker, C. K., Gleason, K., Naai1, R., Mitchell, J. \& Trecker, C. (2012). Increasing knowledge of sexual abuse: A study with elementary school children in Hawai'i. Research on Social Work Practice, 23(2) 167-178.

BBC (2013). Childline to teach all UK primary schools about abuse. Retrieved from http://www.bbc.co.uk/news/uk-24101118

BBC (2014). Jimmy Saville Scandal. Retrieved from http://www.bbc.co.uk/news/uk$\underline{20026910}$ 
Black, M. \& Ponirakis, A. (2000) Computer-administered interviews with children about maltreatment. Methodological, developmental and ethical issues. Journal of Interpersonal Violence, 15 (7), 682-695.

Boynton, P. M. \& Greenhalgh, T. (2004). Selecting, designing, and developing your questionnaire. British Medical Journal, 328, 1312-1315.

Carroll-Lind, J., Chapman, J., Gregory, J., \& Maxwell, G. (2006). The key to the gatekeepers: Passive consent and other ethical issues surrounding the rights of children to speak on issues that concern them. Child Abuse and Neglect, 30 (9), 979-989.

Ellonen, N. \& Poso, T. (2011). Children’s Experiences of Completing a Computer-Based Violence Survey: Ethical Implications, Children and Society, 25, 470-481.

Emerson, L. \& Lloyd, K. (2014) Are children’s views being sought, listened to and taken seriously? Belfast: ARK. Retrieved from www.ark.ac.uk/publications

Fargas-Malet, M., McSherry, D., Larkin, E. \& Robinson, C. (2010). Research with children: Methodological issues and innovative techniques, Journal of Early Childhood Research, 8(2), 175-192.

Finkelhor, D., Vanderminden, J., Turner, H., Hamby, S. \& Shattuck, A. (2014) Youth exposure to violence prevention programs in a national sample Child Abuse and Neglect 38 (4), 677-686. 
Gallagher, B., Bradford, M. \& Pease, K. (2002). The Sexual Abuse of Children by Strangers: Its Extent, Nature and Victims’ Characteristics. Children and Society, 16, 346-359.

Goldman, J. D. G. (2011). External providers' sexuality education teaching and pedagogies for primary school students in Grade 1 to Grade 7. Sex Education: Sexuality, Society and Learning, 11(2), 155-174.

Goodman, R. (2013). Online child and adolescent mental health surveys can be good enough. Social Psychiatry and Psychiatric Epidemiology, 48, 1317-1325.

Heiervang E. \& Goodman R. (2011). Advantages and limitations of web-based surveys: evidence from a child mental health survey. Social Psychiatry and Psychiatric Epidemiology 46, 69-76.

Helweg-Larsen, K. \& Bøving Larsen, H. (2003). Ethical issues in youth surveys: Potentials for conducting a national questionnaire study on adolescent schoolchildren’s sexual experiences with adults. American Journal of Public Health, 93(11), 1878-1882.

Hunleth, J. (2011). Beyond on or with: Questioning power dynamics and knowledge production in 'child-oriented’ research methodology. Childhood, 18(1), 89-93.

Lee, Y. \& Lee, R. M. (2012). Methodological Research on "Sensitive" Topics: A Decade Review. Bulletin de Méthodologie Sociologique,114, 35-49. 
Leonard, M. (2007). With a Capital "G": Gatekeepers and Gatekeeping in Research with Children. In A. Best, (Ed), Representing Youth (pp. 153-169). New York: University Press. Lewis, A., and Lindsay, G. (Eds.) (2000). Researching children's perspectives. Buckingham: Open University Press.

Livingstone, S., Haddon, L., Görzig, A. \& Ólafsson, K. (2011). Technical Report and User Guide: The 2010 EU Kids Online Survey. LSE, London: EU Kids Online.

Lloyd, K. (2012a) Happiness and well-being of young carers: Extent, nature and correlates of caring among 10 and 11 year old school children, Journal of Happiness Studies, 14 (1), 5780.

Lloyd, K. (2012b) Health-related quality of life and children's happiness with their childcare, Child: care, health and development, 38 (2), 244-250.

Lloyd, K. \& Devine, P. (2010). Using the internet to give children a voice, Field Methods, 22(3), 270-289.

Lundy, L., \& McEvoy, L. (2008). E-consultation with pupils-A pilot study. Bangor: Department of Education for Northern Ireland.

Madge, N., Hemming, P. J., Goodman, A., Goodman, S., Kingston, S., Stenson, K. \& Webster, C. (2012). Conducting large-scale surveys in secondary schools: The case of the Youth on Religion (YOR) project. Children and Society, 26, 417-429. 
Morrow, V. (2008). Ethical dilemmas in research with children and young people about their social environments. Children's Geographies, 6(1), 49-61.

Morrow, V. \& Richards, M. (1996). The ethics of social research with children: An overview, Children and Society, 10, 90-105.

Mudaly, N. \& Goddard, C. (2009). The ethics of involving children who have been abused in child abuse research. International Journal of Children's Rights 17, 261-281.

Nicholas, D. B., Lach, L., King, G., Scott, M., Boydell, K., Sawatzky, B. J., \& Young, N. L. (2010). Contrasting internet and face-to-face focus groups for children with chronic health conditions: Outcomes and participant experiences. International Journal of Qualitative Methods, 9(1), 105-101.

O'Cathain, A. \& Thomas, K. J. (2004). "Any other comments?" Open questions on questionnaires - a bane or a bonus to research? BMC Medical Research Methodology, Retrieved from http://www.biomedcentral.com/1471-2288/4/25

Office of the Children’s Commissioner (2012). You have someone to trust. Retrieved from http://dera.ioe.ac.uk/15496/2/Practical_Tips_You_Have_Someone_to_Trust_Final_Sept_201 2\%5B1\%5D.pdf

Radford, L., Corral, S., Bradley, C. \& Fisher, H. L. (2013). The prevalence and impact of child maltreatment and other types of victimization in the UK: Findings from a population 
survey of caregivers, children and young people and young adults. Child Abuse and Neglect, 37, 801-813.

Roberts, C., Currie, C., Samdal, O., Currie, D., Smith, R. \& Maes, L. (2007). Measuring the health and health behaviours of adolescents through cross-national survey research: recent developments in the Health Behaviour in School-aged Children (HBSC) study. Journal of Public Health 15, 179-186.

Shields, C. (2003). 'Giving voice’ to students: Using the internet for data collection. Qualitative Research, 3(3), 397-414.

Stephenson, P., McElearney, A. \& Stead, J. (2011). Keeping safe: The development of effective preventative education in primary schools in Northern Ireland: Summary Report. Northern Ireland: DENI. Retrieved from http://www.deni.gov.uk/final_keeping_safe_overview_report.pdf

Tapscott, D. (1998). Growing up digital. New York, US: McGraw Hill.

Tilbury, F., Gallegos, D., Abernethie, L. \& Dziurawiec, S. (2008). 'Sperm milkshakes with poo sprinkles': The challenges of identifying family meals practices through an online survey with adolescents, International Journal of Social Research Methodology,11(5), 469-481.

World Economic Forum (2012) The Global Information Technology Report 2012 Living in a Hyperconnected World, Switzerland: SRO-Kundig. http://www3.weforum.org/docs/Global_IT_Report_2012.pdf 